\title{
Hereditary Angioedema
}

National Cancer Institute

\section{Source}

National Cancer Institute. Hereditary Angioedema. NCI Thesaurus. Code C84758.

Autosomal dominant inherited disorder characterized by abnormalities of $\mathrm{C} 1$ inhibitor.

Patients present with swelling of the skin, subcutaneous tissues, and mucosa sites. 